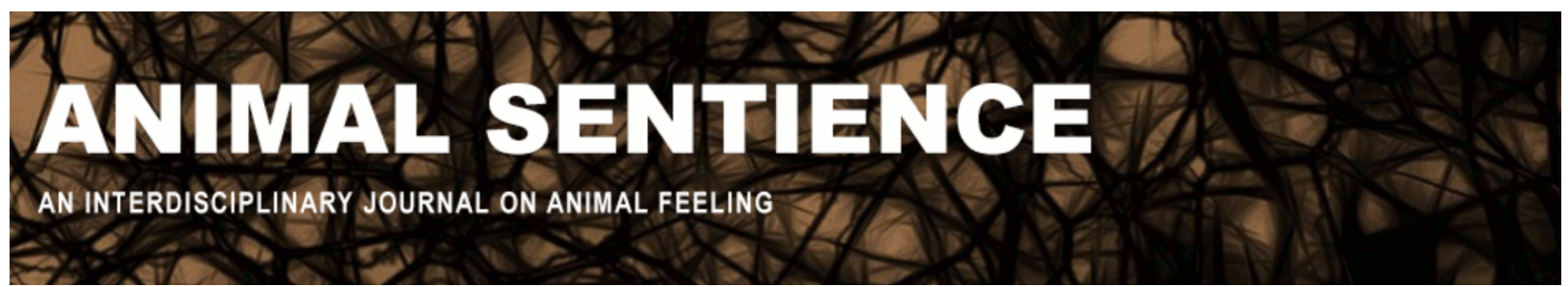

Ristau, Carolyn A. (2017) Self, death, and suicide: Does an animal know of these?. Animal Sentience 20(5)

DOI: $10.51291 / 2377-7478.1290$

Date of submission: 2018-01-05

Date of acceptance: 2018-01-08

(c) (†)

This article has appeared in the journal Animal

Sentience, a peer-reviewed journal on animal

cognition and feeling. It has been made open access,

free for all, by WellBeing International and deposited

in the WBI Studies Repository. For more information,

please contact

wbisr-info@wellbeingintl.org.

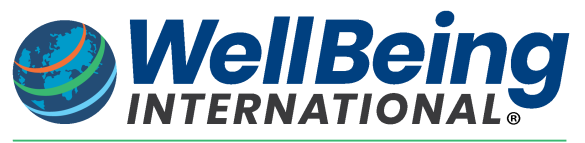

SOLUTIONS FOR PEOPLE, ANIMALS AND ENVIRONMENT 


\title{
Self, death, and suicide: Does an animal know of these?
}

Commentary on Peña-Guzmán on Animal Suicide

\author{
Carolyn A. Ristau \\ Associate, University Seminars \\ Columbia University, New York
}

\begin{abstract}
Peña-Guzmán makes a strong case, using examples from the media and scientific literature, that many captive animals suffer severely. In examining the possibility of animal suicide, he dismisses the need for "reflective self-subjectivity" and "intent" in suicidal behavior. He claims that at least some animals understand "death," citing examples of behavior he deems to be death "rituals." But these can be more simply interpreted. The possibility of animal suicide remains more dubious than Peña-Guzmán suggests.
\end{abstract}

Keywords: animal mind, intention, animal suffering, animal behavior, self

\begin{abstract}
Carolyn A. Ristau is a cognitive ethologist whose research includes field studies of cognition and communication in primates and plovers. She also investigates human ethnopolitical conflict and cooperation, primarily in Africa. Currently, she is writing a biography of the revolutionary scientist Donald R. Griffin, whose 1976 book, The Question of Animal Awareness, was instrumental in creating the paradigm shift in the study of animal mental experience. https://barnard.academia.edu/CarolynRistau
\end{abstract}

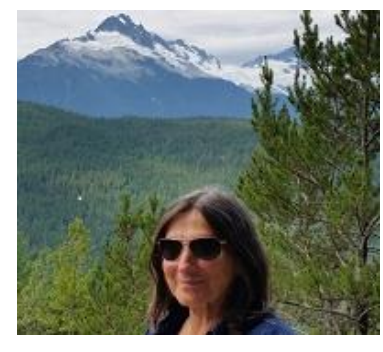

In his daring target article, Peña-Guzmán (2017) confronts some mighty issues: What is self? What is death? What is suicide? And what is the evidence that animals are aware of such matters? He suggests that a "large and growing body of evidence" indicates that the possibility of animal suicide cannot be ruled out (Section 6, p. 18). The evidence, he notes, is anecdotal. That, in and of itself, is not necessarily a flaw, for "anecdotal" can refer to one or a few observations by an experienced and trained observer, or a second- or third-hand "story" passed on and "improved" with each telling ... or anything in between. I would agree that animals engage in self-injurious behaviors; but we understand little about what such behavior means when humans do it and even less when nonhuman animals do it.

\section{The Self}

To reach his conclusion, Peña-Guzmán tackles various arguments against the possibility of animal suicide. One is that to commit suicide requires a sense of self entailing a "specific kind of reflective self-subjectivity" (Section 1.1, p. 2). He attempts to show that some humans committing suicide do not have this sense (e.g., young children; Willett 2014), whereas some nonhuman animals do. He then concludes that this sense of self cannot be a prerequisite for suicide. Peña-Guzmán later raises the issue of "Epistemic Humility": giving the benefit of the doubt to animals and their 
presumed capabilities. The ethologist Donald Griffin (1976), in his seminal book The Question of Animal Awareness, likewise stressed the need for "rough-and-ready," pragmatic, working definitions (pp. 4-6) as scientists attempt to "come to grips" with questions - in his case, the possibility of mental experiences in animals.

We do not understand the sense of self in children who apparently commit suicide, nor do we understand what kind of "reflective subjectivity" animals need to perceive the self as an entity who can exist or not exist. Peña-Guzmán seems to accept the relevance of the "mirror test" (Gallup, 1970) as evidence of the understanding of "self" entailing a "reflexive, self-conscious subjectivity" (Prior, Schwarz \& Güntürkün 2008). The most plausible interpretation of the mirror test is that it indicates a sense of self as a body (Ristau \& Robbins 1982; Ristau 2013), not as a mind, not as an entity who exists now, yesterday, and tomorrow as the same entity.

\section{Intention}

A second issue is that of "intent." Peña-Guzmán proposes a continuum of self-injurious behaviors, which is a reasonable way to consider such behaviors, but it is not clear quite what that continuum is. One pole consists of reflexive behaviors, such as the fatal self-stinging act of the scorpion that has been observed on some occasions when the scorpion was surrounded by fire. But what is the other pole? Intentional action? Almost every discussion of suicide includes a deliberate "intent" to terminate one's life. Peña-Guzmán argues that "intent" is not a very useful scientific concept, suggesting that various theories of psychology avoid it. Behaviorism and neo-behaviorism are obvious examples; they attempt to avoid "intentional acts" through rewards and punishments that reinforce specific behaviors. In contemporary psychology, behaviorism is regarded as inadequate for explaining human and animal behavior. The notion of intent is essential to scientific as well as everyday understanding of many motivated behaviors, including the "compassionate caregiving" of Sichuan snub-nosed monkeys Peña-Guzmán cites in reference to dying. He actually seems to be of two minds about the concept of intent. He dismisses it as a useful construct, but also notes that animals "sustain intentions for long periods of time."

Interesting nuances of suicidal intentions do exist. There are many methods and gradations of self-injury and slow destruction of oneself. Some of these may be intentional, with the aim of ending one's life; others may not have that intention, although the final result may be the same. Very ill, disheartened people may simply not eat, starving themselves to death. The starvation may be due to depression or a deliberate attempt to end one's life. In some cases, even if there were a pistol nearby, the person seeking to die would not use it (Nichols \& Mallon, 2006). These complexities in human suicidal intent may also be relevant in the case of non-human animals.

Other important distinctions surround actions that cause pain. These seem inherently different in meaning from actions that diminish well-being and may result in intentional or unintentional death. This also complicates the notion of a "continuum" of self-injurious acts for human and non-human animals. Pena-Guzman uses some rather unusual definitions (italics are mine):

INTENT: A mental state typically believed to cause the behavior of rational, linguistic agents. 
Such a definition obviously implies human language, rather than forms of animal communication, and immediately excludes animals, before even considering definitions of "rational."

SUICIDAL BEHAVIOR: Self-directed acts that can endanger the wellbeing of an animal or terminate its life-activity.

Suicide may well be on a continuum of self-injurious behaviors (rather than the "continuum of suicidal behaviors" suggested by Peña-Guzmán) but, as noted, diminishing well-being is different from killing oneself, or wanting to.

\section{Animals Understanding Death and Engaging in Rituals?}

To support the possibility that at least some animals understand death, Peña-Guzmán states that "Burial rituals have been observed in various animal species." ${ }^{1} \mathrm{He}$ cites examples of purported rituals surrounding death, particularly among chimpanzees, but also in other species, for example, crows, magpies, captive gorillas, red foxes, elephants, and dolphins. Unfortunately, many of the examples are from popular media, rather than the peer-reviewed literature.

One might ask: What are the details of the observed behavior and of the communication with conspecifics and the observing human? What are the criteria for behaviors to be considered "rituals"? For example, the loudly squawking crows mobbing a human holding a dead crow are apparently described by the researchers studying the behavior as, "potentially chastising the predator, displaying dominance or social learning of the dangerous person or place" (BBC, 2015). Simply put, the birds are "reacting" to the dead conspecific and the potential predator who may have killed it. That is not evidence of a "ritual."

"Rituals" are culturally transmitted acts that, in the case of humans, entail some special significance and meaning for group members. Responses to death can vary. In a group of animals (Smith et al., 1973), there might be a very emotional individual, perhaps a high-ranking adult. Others, especially family members and young, may imitate the behavior, not only in one specific instance, but on various occasions. There may be different reactions to death in different groups. This might be one of many plausible antecedents of rituals, but it is difficult to categorize as "ritual."

In attempting to promote the sensible "Continuist" view of humans and other animals, Peña-Guzmán has been simultaneously very logical and restrictive in his reasoning, but also perhaps overgenerous in his interpretations. I cannot, for example, believe that the term "in denial," which immediately conjures up Freudian-like theories, is appropriate to describe a chimpanzee carrying her dead and decaying infant about with her for days or weeks (which I have indeed witnessed). She is strongly bonded, has deep affection for her infant, whether or not we term it "love," and she keeps it with her, maybe hoping it will recover and act as it usually does.

\footnotetext{
${ }^{1}$ In his commentary, Lester (2017) describes the research of Schaefer (1967) indicating that mice can learn to avoid a compartment in which they have observed a mouse being electrocuted, thereby suggesting that the mouse can understand a notion of "death." As Lester notes, various controls are lacking, in particular, distinguishing between a moving and non-moving state. There is also the impact on a mouse of observing the vocalizing and painful reactions of another mouse during the course of its electrocution.
} 


\section{Conclusion}

Peña-Guzmán has provided many provocative and well-accepted examples of animals' negative emotional states, of caring and self-mutilation. He has challenged our thinking about animal capacities. The ultimate purpose of the target article, I think, is to inspire our own compassion for the well-being of animals in our care, recognizing the misery we may cause them as we keep them in captivity and under stressful conditions. I believe Peña-Guzmán has achieved that aim. Whether the acts of any animal or species can be suicidal still remains an open question, and I am more dubious than Peña-Guzmán.

\section{References}

BBC News. (2015) The birds that fear death.

Gallup, G. G. (1970) Chimpanzees: Self-recognition. Science, 167: 86-87.

Griffin, D. R. (1976) The question of animal awareness: Evolutionary continuity of mental experience. New York: Rockefeller University Press.

Lester, D. (2017) Non-human animal suicide could be tested. Animal Sentience 20(3).

Nichols, S., \& Mallon, R. (2006) Moral dilemmas and moral rules. Cognition, 100(3): 530-542.

Peña-Guzmán, D. M. (2017) Can nonhuman animals commit suicide? Animal Sentience (20)1.

Prior, H., Schwarz, A., \& Güntürkün, O. (2008) Mirror-induced behavior in the magpie (Pica pica): Evidence of self-recognition. PLoS Biology, 6: 1642-1650.

Ristau, C. A. (2013) Cognitive ethology, Advanced Review. WIREs Cognitive Science doi:10.1002/wcs.1239.

Ristau, C. A., \& Robbins, D. (1982) Language in the great apes: A critical review. In J. S. Rosenblatt, R. A. Hinde, C. Beer, \& M.-C. Busnel (Eds.), Advances in the study of behavior (Vol. 12), pp. 142-255. New York: Academic Press.

Schaefer, H. H. (1967) Can a mouse commit suicide? In E. S. Shneidman (Ed.), Essays in selfdestruction, pp. 494-509. New York: Science House.

Smith, W. J., Smith, S. L., Oppenheimer, E. C., de Villa, J. G., \& Ulmer, F. A. (1973) Behavior of a captive population of black-tailed prairie dogs. Behaviour, 46: 189-220. 